\title{
PROSPECTO PARA UN DESARROLLO "ARTIFICIAL" DE LA FILOSOFÍA
}

\author{
Roberto Pizarro Contreras \\ rpizarroc@hotmail.com
}

\begin{abstract}
RESUMEN / ABSTRACT
En este artículo se analizan algunas alternativas posibles para el devenir de la filosofía. Los pronósticos de la filosofía continental y la filosofía analítica suponen dos caminos. Un tercero lo ofrece la eventualidad de una filosofía desinstitucionalizada y asistemática. A partir de ellas intentará derivarse una cuarta opción, la cual, si bien inusitada en su contextura futurista al prospectar una potencial utilidad de las tecnologías de inteligencia artificial al quehacer filosófico, serviría al propósito de dar unas pautas para una reivindicación civilizatoria de la filosofía, si bien con importantes consecuencias epistemológicas en relación con los métodos de producción académica presentes.
\end{abstract}

Palabras Clave: filosofía continental, filosofía analítica, tecnociencia, capitalismo de datos, inteligencia artificial (IA).

\section{PROSPECTUS FOR AN “ARTIFICIAL" DEVELOPMENT OF PHILOSOPHY}

In this article some possible alternatives for the evolution of philosophy are analyzed. The forecasts of continental philosophy and analytic philosophy assume two paths. A third is offered by the eventuality of a deinstitutionalized and unsystematic philosophy. From them, a fourth option will try to be derived, which, although unusual in its futuristic context when prospecting a potential utility of artificial intelligence technologies for philosophical work, would serve the purpose of giving guidelines for a civilizing claim to philosophy, although with important epistemological consequences in relation to the present academic production methods.

KEYWORDS: continental philosophy, analytic philosophy, technoscience, data capitalism, artificial intelligence (AI).

I. Una renovación filosófica basada en la herencia y método de los grandes sistemas filosóficos: La propuesta "tradicionalista" de la filosofía continental

$\overline{R A}$ No tengo intención de llevar a cabo aquí una selección de trabajos que pudieran etiquetarse bajo el rótulo de "filosofía continental", sino más bien de sintetizar uno de los ensayos de quien es reconocido como uno de sus más renombrados exponentes, el filósofo alemán Jürgen Habermas, recogiendo de él lo que me parece mejor representa el espíritu de renovación de la tradición filosófica emancipado de los avatares de la técnica y sus sistemas. 
Habermas plantea en su pregunta “¿Para qué seguir con la filosofía?”-Wozu noch Philosophie? (Habermas 1971, pp. 11-36) -cuatro pretensiones históricas de la filosofía (desde sus orígenes hasta Hegel) sin las cuales este modo de ser se habría "desnaturalizado" y convertido en mera crítica, entendida esta, no en clave kantiana, es decir, no en tanto que investigación que tiene como principal preocupación establecer los fundamentos y límites del ejercicio de la razón, sino como un enjuiciamiento orientado a corregir los grandes desarrollos teoréticos de la tradición filosófica sin llegar él a estatuirse como un desarrollo por sí mismo. Dichas pretensiones son:

1. La fundamentación última de la realidad.

2. La relación indefectible entre teoría filosófica y praxis.

3. La exigencia de totalidad del conocimiento metafísico y al mismo tiempo la interpretación religiosa del mundo.

4. El elitismo y el personalismo en el desarrollo teórico-filosófico.

Revisemos cuanto ocurre cuando se renuncia a estos designios.

En el primer caso, cuando la filosofía renuncia a la fundamentación última de la realidad, se da entonces una fundamentación afirmativa del ente en su totalidad y se escinde la filosofía primordial del resto de saberes, como habría acontecido entrado el siglo XIX con el ascenso del modo científico de conocer. En otras palabras, nos afirmamos a las cosas tal como se nos aparecen y efectuamos hipótesis sobre ellas en función de esas apariciones y, entre otras variables, su frecuencia, la que mensuramos y reducimos a una probabilidad numérica que nos permite modelizar los fenómenos a los que la cosa en cuestión se haya aparejada. Cuando se dice, por ejemplo, que los estudios epidemiológicos estiman que el trastorno de agorafobia está presente en el 5,3\% de la población general (Rubio 2018, p. 54), estamos aludiendo a un comportamiento promedio, que en sí es una medida estocástica o probabilística de la realidad. Luego esta es una de las formas posibles del empirismo (un paso más allá de Hume, si se quiere, al considerar varios hechos semejantes como si fueran las repeticiones de uno solo) por la que nos representamos la realidad cercenando otras posibilidades que tienen otros presupuestos de base. En este sentido, si la filosofía se cuestiona el pensar mismo en la búsqueda de la verdad universal, no tiene caso asentar un único presupuesto como el válido para iniciar el tránsito hacia tal conocimiento absoluto, a menos que se tenga plena certeza de que no cabe otro, lo que de suyo parece improbable.

En el segundo caso, si la filosofía prescinde de la praxis social, pasa a verse a sí misma, directora, como sustrato reflexivo de la actividad social y es incapaz de proveer una imagen sociocósmica del mundo. Ocurre algo análogo a lo mentado en el párrafo precedente, en circunstancias de que al despreciar ahora el componente empíricosocial, se amputa lo que algunos autores como Juan Ramón Fuentes Jiménez llaman en la filosofía utilitarista de John Stuart Mill “el dato antropológico y ontológico de la realidad diversa" (Fuentes 2013, p. 315). El propio Kant, en su idealismo trascendental, vindicaba que ni la percepción sensible ni el entendimiento, por sí solos, pueden derivar conocimiento: la primera suministra contenidos sin forma (caos), el segundo formas sin 
contenido (ilusiones); ambos elementos son indispensables en su modelo de conocimiento (Solé 2019, p. 56). De lo contrario, se incurre en un idealismo rudimentario que hace justicia a la archicitada máxima platónica que ordena jerárquicamente de arriba abajo el Estado Ideal:

Vosotros, ciudadanos del Estado, sois todos hermanos. Pero la divinidad, cuando os moldeó, puso oro en la mezcla con la que se generaron aquellos capacitados para gobernar, siendo de tal forma del más alto valor; plata en los auxiliares; hierro y bronce en los campesinos y demás artesanos (Platón 2019, c.p. Dal Maschio, p. 95).

En cuanto a la tercera pretensión, sobre la exhaustividad metafísica y la interpretación religiosa del mundo, dice ella relación con la apuesta que en última instancia hace un filósofo acerca del sistema filosófico que más juzgara fidedigno o eficaz en su aplicabilidad a lo real. La exhaustividad metafísica y la interpretación religiosa son interdependientes también: cada estampa del devenir humano sobre su universo presupone un salto de orden doctrinario, y esto es lo que otorga, a mi parecer, la posibilidad de una filosofía constructiva o articuladora de lo real y no tan solo una filosofía constatadora o dubitativa, en tanto y en cuanto una construcción filosófica hace justicia, por decirlo de algún modo, a su religión subyacente, aviniéndose lo mejor posible con su fundamento absoluto hasta que los cuestionamientos subjetivos del mismo lo tornan obsoleto. Es así que si se rechaza esta postura, no quedaría otra cosa, según Habermas, que el utopismo y el interés político por la emancipación más bien que ajustarse a lo axiomático, lo esencial, y hacerse uno con él. Un ejemplo de lo más vigente son las acusaciones que contra el capitalismo contemporáneo se estilan, tachándolo de "religioso" en virtud del neoliberalismo sobre el que sienta sus bases, el cual no se cuestionaría acerca de sus orígenes liberales ni la cobertura total de su ideario sobre los hechos de la realidad social, sino, por el contrario, produciría compulsivamente sobre la pretensión ya satisfecha que implica la asunción ciega de una mano invisible todopoderosa ordenadora de los fenómenos, sobre un "principio místico", como dice Samuelson cuando critica a la suerte de Deus ex machina, o automatismo de la mano invisible de Adam Smith en neoliberales como Hayek (Segovia 2016).

Por último, de proscribirse la pretensión de elitismo y personalismo en el desarrollo teórico-filosófico que criticaron Adorno y Horkheimer, esto conllevaría la autoilustración universal y la dimisión de la filosofía tal cual la conocemos, como reza el dictum marxista de abolición de la filosofía: la filosofía, si ha de llevarse a la práctica, tiene entonces que ser suprimida.

Para resumir, asimilaré didácticamente los resultados de estos eventos de prescindencia (al menos cuando sobrevienen los tres primeros) a la trama de la celebérrima serie de anime policíaco Psycho-Pass (サイコパス) (Shiotani et al. 2014). Esta se ambienta en un Japón futurista y, para nuestros efectos, versa sobre una inteligencia artificial (IA) denominada Sibyl, que mantiene el orden y la estabilidad social a través de la medición de un coeficiente psicopático per cápita de la ciudadanía (psycho-pass), el cual, de desviarse, gatilla la alerta inmediata de los subsistemas de atención primaria de salud mental, si no la directa aniquilación del ciudadano "enfermo" en los casos no 
susceptibles de tratamiento. El uso de este recurso informal no es antojadizo, como se verá más adelante, sino que responde al modelo "artificialista" de producción filosófica que se explicará en el último punto.

Primero, no hay en la realidad de Psycho-Pass una fundamentación última de la realidad, sino toda fundamentación se hace sobre la base de la todoabarcadora e inamovible categoría de "coeficiente de psicopatía". Segundo, la praxis está subordinada a la crítica que en función del psycho-pass se lleva a cabo y tan fuerte es el influjo de este que su nombre se halla en el repertorio lingüístico cotidiano de la población civil. Tercero, no es raro que en función de lo anterior no haya una imbricación entre el empeño metafísico y el religioso y, pues, resulte por defecto, no una utopía, sino una distopía que tiene de trasfondo, como se revela hacia el final del anime, a una superinteligencia Sibyl que es en verdad un macrosistema de cerebros biológicos de psicópatas que detenta el poder político bajo la fachada de una tecnología social que administra el mecanismo de control Psycho-Pass. Cuarto, cumple empero con la condición de elitismo y personalismo en el desarrollo teorético de su intento de filosofía social: los cerebros componentes de Sibyl son la directriz universal de conocimiento.

Por último, el diagnóstico que hace Habermas sobre la filosofía -hacia la época en que escribe su ensayo- sitúa a esta dentro del ámbito de la conciencia pública, con una influencia no despreciable (bien que bebiendo parasitariamente de los clásicos de la filosofía, es decir, derivando de ellos ingeniosas e interesantes variantes de sus desarrollos), así como en los campos de crítica y de soporte a la utilidad tecnocientífica; cuando es crítica, lo hace desde una oposición al materialismo fundamentalmente; cuando funge como soporte, lo hace desde el "cientifismo", que Habermas entiende como la fe de la ciencia en sí misma, es decir, la convicción de que en adelante no podemos concebir a la ciencia como una de las posibles formas del conocimiento, sino que hemos de identificar conocimiento y ciencia. (La empresa cientifista es la que llevarían a cabo, en sus palabras, aquellas escuelas de la filosofía analítica que continúan las intenciones fundamentales del Círculo de Viena).

Por supuesto, Habermas no pretende reivindicar estas pilastras cuya exclusión modificó estructuralmente a la filosofía para ponerlas, por decirlo de algún modo, como estaban. Tampoco pretende deshacerse de ellas sin más. Más bien lo que propone es, entre otras cosas, utilizar la maquinaria tecnocientífica y someterla a una crítica de sí misma, según lo cual no solo habría una remisión curativa del imperio que la tecnociencia ha impuesto sobre el mundo sino además existiría una base pensativa disponible para su articulación como ninguna filosofía antes la habría tenido (un acervo enorme de data empírica para ser pensada). Es así que se sigue haciendo ciencia, no bajo el mandato filosófico, sino contando con su moderación, lo que revalidaría civilizatoriamente, en última instancia y para el propósito que se ha trazado en el titular de este trabajo, a la filosofía. 
II. Una renovación filosófica que actualice sus categorías al alero de la tecnociencia y la industria capitalista-digital que la soporta: La propuesta "cientificista" de la filosofía analítica

Procederé de la misma manera con la filosofía analítica, valiéndome de uno de los trabajos de uno de sus más prestigiosos autores, en este caso el filósofo norteamericano John Searle. La empresa será más sencilla esta vez, en circunstancias de que el ensayo serleano se intitula The future of philosophy (Searle 1999), atañendo de esta manera directamente al propósito de prospección perseguido.

Para Searle, célebre por sus contribuciones a la filosofía del lenguaje, el error filosófico de la época corresponde a un sesgo epistémico: suponer que las cuestiones sobre el significado son cuestiones sobre las circunstancias en las que la gente pronuncia expresiones (en concreto, los seguidores de Frege habrían transformado las preguntas sobre el significado en preguntas sobre el conocimiento del significado). Es algo en lo que el propio Wittgenstein, monumento de la filosofía analítica, habría incurrido en su primera etapa al corresponder mundo y lenguaje en la famosa proposición 5.6 de su obra Tractatus Logico-Philosophicus: "Los límites de mi lenguaje son los límites de mi mundo". Así una ciencia del lenguaje está sujeta a los inconmensurables contextos en los que la palabra podría aparecer. Un ejemplo aún más paradigmático lo constituye, si se quiere, la semiótica de Umberto Eco, para quien las palabras constituyen "enciclopedias" (Eco 1993, pp. 23-39); enciclopedias que se entretejen con otras enciclopedias. El semiólogo italiano nos dice que comúnmente creemos que las palabras están codificadas como el significado en un diccionario, pero de lo que se trata es de entender el significado de la palabra como una entrada que dispara toda una sugerencia de una historia o entramado de experiencias que difieren de agente en agente. Además, las palabras serían programas narrativos potenciales que dependen fuertemente del contexto (la circunstancia en que la palabra emerge) y el cotexto (el advenimiento de una experiencia que rearticula el significado de la palabra para uno o más contextos en los que ella aparece, añadiendo además un nuevo contexto al repertorio). Eco, como se aprecia, pone de manifiesto una trama infinita de opciones al reunir en un significado la palabra y los contextos a los que esta adscribe, y también al establecer una tercera dimensión relativa a las experiencias de cada sujeto.

Daniel Dennett reconoce y denuncia estos constructos difusos y divergentes presentes, por ejemplo, en varios autores de la filosofía de la mente (incluido él mismo en su primer libro, advierte) a través de la ola de entusiasmo que les ha engendrado la IA aplicada en torno a la funcionalidad de los "modelos conexionistas" (Dennett 1999, p. 332). Al respecto señala:

Quizá el mejor ejemplo actual de este beneficio [de poder explotar extensiva e intensivamente un modelo sobre la base de su realización fáctica contingente, dada en este caso por los desarrollos de IA del último tiempo] es la ola de entusiasmo hacia los modelos conexionistas. Durante años, los filósofos de la mente han estado dirigiendo sus manos, vaga y esperanzadamente, en dirección a esos modelos, completamente incapaces de concebirlos en detalle, pero seguros hasta sus huesos de que eso tenía que ser posible. 
Searle cree además que nos encontramos en una situación semejante a la que se encontraron Sócrates y Platón luchando contra el escepticismo. Salva que Aristóteles, sin embargo, nunca vio esta corriente como una amenaza a su proyecto general de realizar una filosofía constructiva, sistemática y teórica. De ahí su convicción de que nosotros poseemos asimismo las herramientas y de que nos hallamos en condiciones de poner en marcha una especie de aristotelismo del siglo XXI. Propone saltar del "cómo sabes" cartesiano al "qué quieres decir" de Russell, Moore, Wittgenstein y Austin. De lo que se trata es de aprehender, sin ambages, el estado consciente concreto que determina una intencionalidad subjetiva y esclarecer tanto como sea posible la mecánica (neurocognitiva) que le determina.

Su prospecto de la filosofía que adviene está compuesto, en consecuencia, por los siguientes problemas:

1. La relación mente-cuerpo.

2. La filosofía de la mente y la ciencia cognitiva.

3. La obsolescencia de la filosofía del lenguaje.

4. La filosofía de la sociedad y su fundamento analítico.

5. La ética como subrama de la razón práctica.

6. La filosofía de la ciencia y la explicación del universo.

Ellos se resumen en la cuestión de que es posible una ciencia de la conciencia, porque la objetividad epistémica no excluye la subjetividad ontológica de los problemas de estudio. Tal ciencia tendría como base a uno de los más productivos programas científicos, el de la ciencia cognitiva, cuyo estudio de objeto fundamental es la intencionalidad en todas sus formas. Searle propone para ello una teoría de campo consciente basal o background, que a partir de estímulos dados permita neurobiológicamente, a nivel tálamo-cortical, reproducir la experiencia consciente unificada, en oposición a la teoría científica de correlato neurobiológico de la conciencia (NCC) que estudia la misma a la manera de ladrillos, como suma de los sistemas funcionales (audición, olfato, etc.).

Lo anterior no significa en modo alguno que se tendrán menos preguntas filosóficas, sino que en la medida en que se resuelvan las presentes surgirán tantas otras o más, pero es esto mismo lo que haría a la filosofía más filosófica. Así, la filosofía del lenguaje, al no ser capaz de dar una definición satisfactoria de lo que el significado es ni de aportar más problemas aparte de aquel insoluble que supone aparejar el significado de una expresión a su circunstancia, trascendería al dominio de la pragmática y allí se quedaría generando contribuciones.

Searle apuesta, en fin, a que tendrá que hacerse una revisión del vocabulario de sentido común con que se describen procesos relativos a pensamientos y acciones, como en el caso de la memoria, histórica y psicologistamente concebida como una recuperación de experiencias pasadas y de conocimiento, que seguramente, sostiene el filósofo, acabará tratándose biológicamente como un proceso creativo. 
La mayor parte de los filósofos, como también la mayor parte de la gente instruida de hoy en día, concibe la causalidad como una mezcla de la mecánica newtoniana y del sentido común. [...] Sabemos que a cierto nivel de abstracción esto no es correcto, pero aún no hemos reemplazado nuestra concepción del sentido común con una concepción científica más sofisticada. Creo que ésta es la tarea más interesante de la filosofía de la ciencia del siglo XXI.

De este modo, de la mano de una racionalidad científica más elaborada, los filósofos estarían en condiciones de dar un paso más allá en la comprensión de los fundamentos y problemas de la sociedad y de la ética, como así podría zanjarse una deuda histórica ("escandalosa", dice exactamente el pensador analítico) en relación con la explicación del universo a partir de los fenómenos de la mecánica cuántica (y otros de calibre científico) desde la filosofía de la ciencia, entre otros.

Raya para la suma: Searle se acoge suo modo a la máxima wittgensteiniana "En filosofía el ganador de la carrera es aquel capaz de correr más despacio. O quien alcanza la meta en último lugar" (Wittgenstein 2017, c.p Carmona, p. 7), dado el ritmo que imprime a la productividad del proceso de elucubración filosófica al reformular sus pilastras según los sistemas de la tecnociencia. Y es que esta última se construye según aportes modestos, que quedan bien representados por la rapidez de estructuración de los grandes repositorios de artículos académico-investigativos. Por su parte, el proceso mismo de renovación de las categorías de la filosofía sería también de largo aliento.

Adicionalmente, es interesante la abstención que Searle lleva a cabo en este ensayo, leído en el marco del evento del milenio de la Royal Society, sobre el contexto capitalista en que ejecuta su prospecto. Y es que para él existe una necesidad apremiante de una filosofía de la sociedad.

Creo que debemos tener una filosofía social que sea a las ciencias sociales lo que la filosofía de la mente es a la psicología y la ciencia cognitiva o la filosofía del lenguaje a la lingüística. [...] Creo que cuando las cuestiones de ontología social hayan sido resueltas apropiadamente, se aclararán las cuestiones de la filosofía social, a saber la naturaleza de la explicación de las ciencias sociales y la relación de la filosofía social con la filosofía política.

De ahí que esta renovación filosófica sea susceptible de circunscribirse dentro de la arquitectura social vigente, puesto que el pensador norteamericano parece hacer una especie de epojé del capitalismo, a la espera de poder dictaminar con propiedad racional su pertinencia como base social del desarrollo intelectual.

Finalmente, Searle difiere de las pretensiones históricas que Habermas ha reconocido en la filosofía únicamente en el incumplimiento de la primera de ellas, al clausurar, por ejemplo, otras formas posibles de la disciplina por calificarlas de improductivas, como hace con la filosofía del lenguaje.

Desde el punto de vista habermasiano, no es que Searle piense distinto al filósofo continental, sino que probablemente la filosofía de este último sea mucho más exhaustiva y, por lo tanto, más abstracta en su apertura hacia diferentes posibilidades. Si es posible 
graduar a la filosofía, el filósofo analítico se movería a buen recaudo entonces sobre uno de los trazos posibles hacia la estrella madre que, digamos, es la verdad, sin por ello hallarse más distante de ella; más que dubitativa, su filosofía sería constructiva o propositiva. En Habermas, no obstante, duda y tránsito hacia la verdad se entienden dialécticamente, o así al menos habría hecho la filosofía hasta Hegel.

\section{Una filosofía asistemática derivada de otras disciplinas o expresiones sociales}

No existe registro de autores que se aventuraran a postular que nunca antes el espíritu filosófico había estado más en boga de la ciudadanía ni mucho menos que en ella pudiera ser más productivo que bajo su forma institucional. (Podría pensarse incluso que tal aserción es un insulto a la inteligencia, que peca de un optimismo ingenuo o de un rebuscamiento extremado.) Yo me atrevo a esgrimir esta posibilidad, no obstante, amparándome en los hechos que siguen:

1. La reingeniería de la empresa.

2. La naturaleza de los movimientos sociales contemporáneos.

3. La presencia explícita de la filosofía en el arte contemporáneo.

Explicaré cada uno, queriendo con ello justificar, no que una filosofía sistemática ya no es necesaria, sino, por el contrario, que existen fuentes aun no sistematizadas por ella desde las que puede nutrirse e incluso reformarse.

Lo que he denominado "reingeniería de la empresa" dice relación con los correctivos que el capitalismo aplica sobre sí mismo, lo que Habermas reconoce como un dispositivo recursivo cada vez más insostenible de "autoparchado" del sistema en Problemas de legitimación en el capitalismo tardío (Habermas 1999, p. 79). Para aterrizar aquella idea, quisiera colgarme de los planteamientos de un autor corporativo, el belga Frederic Laloux, y de su bestseller Reinventar las organizaciones (Laloux 2017).

En la mentada obra, el autor ha puesto de manifiesto la necesidad de lograr una organización (empresa) multiforme, capaz de reinventar su forma lo mismo que su contenido, pues sería ello la tabla de salvación para aprehender y manejar la complejidad creciente del medio.

El modelo que propone rige no solo para la empresa -que en un contexto capitalista es, digamos, la forma de organización por antonomasia-, sino para cualquier otro tipo de organización que intente consumar sus objetivos.

El mérito de Laloux reside en su esfuerzo por establecer una genealogía y tipificar las distintas clases de organizaciones que han emergido en el curso de la humanidad, a fin de implementar el modelo histórico en la circunstancia propicia. En efecto, como si el espíritu historicista de Maquiavelo, Hegel o Marx le hubiera sido inoculado, Laloux lleva a cabo en su libro una genealogía de los tipos históricos de organizaciones humanas. 
Arranca, digamos, poniéndolo en términos filosófico-políticos, con el homo homini lupus de Plauto (rescatado, recordemos, por el filósofo Thomas Hobbes en De Cive, lo que servirá luego para redondear su teoría contractualista), es decir, desde el hombre primitivo que se une por miedo y conveniencia a los otros para conformar una tribu (organización roja), pasando por el dogmático y ultrajerarquizado Estado real y religioso (organización ámbar), a continuación a través del Estado moderno y la empresa del capitalismo industrial (organización anaranjada), bien descritos los dos por Marx en su crítica de la economía política, y, por último, por medio de la flexible y sofisticada empresa neoliberal de nuestros días (organización verde), para arribar al cabo en la menos opresiva de las formas de organización, a la que denomina "organización turquesa", que convergería en una especie de inteligencia colectiva.

Luego sería la organización turquesa la clase culminante de sistema social, que buscaría prescindir absolutamente de los rangos y escalafones, sin por ello desmedrar la efectividad del cometido empresarial. En este modelo la gerencia es individual y cada quien entiende su propósito y se consagra, pues, a su consumación de cara al propósito general del corpus. La metáfora que rige aquí es la del organismo vivo, en tanto se trata de organizaciones cuyos roles autoevolucionan, logrando así que las apetencias y la efectividad de los individuos se condigan con la misión organizacional y viceversa.

Dicha autoevolución se logra en función de un "proceso distribuido de toma de decisiones", que lejos de asimilarse a una democracia en el sentido pedestre de tolerar todas las opiniones, busca el asesoramiento racional de todas aquellas partes que influyen en la ejecución del trabajo de un sujeto, enriqueciendo de esta forma su perspectiva.

Laloux, lejos de ser idealista, o bien, materialista en clave marxista, se comporta pragmáticamente al defender la existencia de cada tipo de organización en el contexto particular que le toca atravesar, si bien le da preponderancia a la emergencia de las organizaciones turquesa por el papel global que les cabría desempeñar en el futuro mediato. Además, puesto que la forma de conceptualizar los objetivos de esta clase de organización está sujeta muy sensiblemente a los cambios del medio en que opera, el tipo de biométrica (mediciones sobre la vida) que propugna y que afecta a las subjetividades está muy en línea con los teóricos postmodernos de la razón, quienes conciben esta como una noción que está constantemente enriqueciendo y reformulando su fundamento a través de la evidencia empírica que le es dable aprehender. Se dice, entonces, que los objetivos organizativos están constantemente reinterpretándose (“optimizándose”, en la jerga corporativa) a la vez que se controlan intensivamente y, además, los controles que se establecieran han de hallarse en función de esas reinterpretaciones. He ahí, en la plasticidad de forma y contenido, una definición actualizada para la sustentabilidad empresarial por excelencia.

Lo que tiene de filosófico esta "reingeniería empresarial", acaso no se haya atisbado aun, consiste en que la empresa, en tanto comunidad de individuos, es capaz de cuestionarse sus fundamentos incesantemente en aras de descubrir cuánto se debe a sus hacedores (respecto a la intención o mandato originario de ellos), cuánto al medio $\mathrm{y}$, en definitiva, acercarse progresiva e inintencionadamente a una razón de ser que es más humanista que capitalista. Un ejemplo emblemático acerca de esto es el cambio 
de nombre a que se han visto forzadas las gerencias de Recursos Humanos (RR.HH.), tratando de humanizar el mensaje de su gestión con un propósito de fidelización del empleado, aun cuando la reducción técnicamente disponibilizadora de las personas por parte del sistema perdura; es común hablar hoy de "Gerencia de Personas" o incluso, como es el caso de Coca-Cola, de "Gerencia de la Felicidad” (Aranda 2019).

El mismo ánimo puede leerse, de otra parte, en algunos de los movimientos sociales contemporáneos.

La igualdad de género, tanto en la lucha feminista como en lo relativo a la diversidad sexual, ha venido a poner en cuestión el canon de ser humano, y queda clara la dirección en la que se orienta el cambio si concedemos que antes conocíamos universalmente a aquel como "hombre" (la literatura actual nos habla sin distinciones de "humanos" o "existencias"). A propósito, hoy se vuelven indefectibles, entre otras, obras como la de la francesa Simone de Beauvoir, para quien ser "mujer" es el resultado de una construcción sociocultural impuesta que ha impedido al género, desde un punto de vista existencialista, desarrollarse en plenitud y, en cambio, la ha calzado opresivamente en un molde en el que asume características privativas que llega a juzgar inherentes a su género ("las mujeres somos más chismosas que los hombres", sería un ejemplo de esta laya de falacias viralizadas e internalizadas al fin por muchas mujeres), como señala Sánchez (2019, pp. 8-11); o el proyecto filosófico de la norteamericana posestructuralista Judith Butler, para quien la base de la libertad está en la igualdad, cuestión que bien comprobó en 2018 cuando se recolectaron cientos de miles de firmas en su contra, se quemó una imagen demonizada suya y tuvo un recibimiento hostil al arribar en Sao Paulo en la antesala de una conferencia donde expondría sus ideas. "Pedófila" fue el insulto que a su retorno a los EE.UU. le espetó infundadamente un manifestante al dirigirse a la sala de embarque en el aeropuerto brasileño, posiblemente queriendo con ello discriminar su condición de lesbiana, mujer, judía, queer y, por qué no, de filósofa también (Reguero 2017).

Sin entrar en detalles, el transhumanismo, por su lado, ha puesto en cuestión los límites de la morfología humana de cara a su mejoramiento cibernético, como así también la durabilidad del ser humano en cuanto homo sapiens.

Y, en definitiva, la lucha medioambiental y las recientes crisis virológicas del A(H1N1) y el COVID-19 han venido a jaquear el presupuesto antropocentrista de subyugación de los entes del mundo a la lógica técnico-extractivista impuesta por la raza humana y que alcanza su máxima expresión en el estadio presente del capitalismo global.

Nunca antes el ser humano se había enfrentado a tantos polos de cuestionamiento de sí mismo con miras al cambio, al punto de que con ello podría incluso dejar de ser lo que es (cuando menos para el transhumanismo y la probabilidad de extinción que introducen también las pandemias).

Finalmente, no puedo dejar de señalar la presencia de la filosofía, ya no en forma tácita, sino explícitamente, y de forma no académica, en el arte popular.

Ya he mencionado a Psycho-Pass, la célebre serie de anime de distopía, cyberpunk y ciencia ficción de la primera sección. En ella se aprecian referencias explícitas a 
Platón, Rousseau y Kierkegaard, por ejemplo, las cuales son expuestas de una forma que resulta amena para la asimilación de los tópicos que se abordan de cada uno de estos filósofos.

Desde la vereda estética sería posible también recoger los prospectos de institucionalización de una IA de alcance planetario, en cuanto a su modo de despliegue (performance) y los riesgos inherentes a él. Entre las producciones artísticas que se podrían emplear para este análisis, se cuentan, entre muchas: las supercomputadoras Sibyl, MAGI y Sosai X de la series de anime Psycho-Pass, Neon Genesis Evangelion y Fuerza G: "Guardianes del Espacio" (Gatchaman), respectivamente; Mother de la nave Nostromo y APOLLO Central AI, ambas del universo Alien; MULTIVAC, que figura en diferentes relatos de la obra de Isaac Asimov; HAL 9000 de la película "2001: Odisea en el espacio".

Si alguien piensa que académicamente un tipo de investigación que bebiera de estas referencias solo podría hacerlo "muy accesoriamente" y como parte de un trámite investigativo susceptible de reformulaciones contingentes ulteriores, debería espabilar y apreciar la seriedad con que el filósofo francés Éric Sadin aborda, por ejemplo, a HAL 9000 para conducir su obra La humanidad aumentada: La administración digital del mundo (Sadin 2018), que trata la mutación decisiva en nuestro vínculo con la técnica, considerando que mientras que su vocación ancestral habría consistido en actuar como una prótesis de las insuficiencias del cuerpo, hoy su capacidad cognitiva le conferiría el inquietante rol de gobernar a los seres y las cosas.

\section{Una propuesta para la producción y unificación humano-computacionales de los desarrollos filosóficos históricos y presentes}

No me propongo otra cosa en este apartado que describir, aunque sea someramente, lo que sería una filosofía que sea a la vez académica, histórica, grandiosa (en el sentido de un sistema a gran escala, de amplio y creciente alcance) y popular, asentada en una cultura tecnocientífica y capitalista-digital, o una filosofía nueva que ostentara en un comienzo todas estas características. En otras palabras, intentan reunirse sintéticamente los tres prospectos de filosofía mencionados en los apartados precedentes y superar las exclusiones recíprocas que se originan por la naturaleza de sus procedimientos, si bien siempre a favor de un esquema de filosofía sistemática. Con todo implicaría acaso la obsolescencia de la filosofía tal como la conocemos al beber ella de manera intensiva del recurso tecnológico y, como se apreciará, introduciendo un dilema epistemológico al "aumentar" los alcances del conocimiento posible.

Comenzaré señalando que no está claro que una filosofía dubitativa-constructiva como la habermasiana (no digo "crítico-constructiva", ya que entiendo la crítica en un sentido más restringido que la duda o cuestionamiento general) sea más rendidora en comparación con otra que, como la de Searle, es "progresista" o se construye "sobre seguro", es decir, con suma especificidad en el esclarecimiento de los conceptos y la imbricación lógica de ellos (conceptos que, en definitiva, al esgrimirlos, la intencionalidad que les subyace no dé lugar a acepciones o equívocos). Ni tiene por qué serlo, salvo 
que estuviera resuelta ya la tesis de una naturaleza utilitaria de la filosofía, es decir, que deba exigirse a la misma cada vez una ganancia, un rédito cognitivo con la menor probabilidad de ser retrotraído más tarde para ser desmentido, por minúsculo que el mismo fuera en ocasiones. Por consiguiente, sería arbitrario aventurarse sin más por un camino en lugar del otro. Eficacia y eficiencia, como se observa, se contraponen acá: no porque un sistema se construya con el más eficiente empleo de los recursos, será al cabo más eficaz (certero o cognitivamente "bueno" para la filosofía).

Tampoco la correcta filosofía dependería de su grado de abstracción. Una filosofía tan abstracta podría ser tan inútil que no sirviera más que para la contemplación absoluta de su non plus ultra. La filosofía no puede ser en modo alguno pura contemplación. Las ideas conllevan efectos inevitablemente, ya sea para quien las esgrime o su interlocutor, haciéndole perseverar o no en su posición frente al mundo. Rara vez una filosofía pasa desapercibida. Piénsese en la lógica aristotélica: sin ella nos faltaría la claridad racional necesaria para someter a escrutinio los discursos y poner en evidencia las falacias. Piénsese asimismo en el maquiavelismo de la ciencia política moderna y el guiño a ella que se observa en ciertas tácticas de la literatura corporativa que se sugieren a los ejecutivos, por ejemplo, "la presión", consistente en el uso de alertas, peticiones repetidas y amenazas, y "las coaliciones", por medio de las cuales se busca enlistar la ayuda de otras personas para la consecución de un fin determinado (Robbins y Judge 2009, pp. 482-515).

Frente a estas previsiones, el justo medio aristotélico buscaría una solución más armónica. Pero un término secular como el "justo medio" tampoco es necesariamente legítimo por la mera extensión de su vigencia, por insolente que resulte el juicio. De hecho, podría haber tantos justos medios como personas y el que se impusiera al cabo podría solo ser "justo" para el que comulgara con él e "injusto" para todo el resto. Con esto no quiero decir que el justo medio aristotélico sea desechable, sino quiero patentizar la posibilidad de probar otros métodos de filosofar, si tal cosa fuera posible (en virtud de ello ahora este trabajo tendría tanto de prospecto como de manifiesto). Rescato en este sentido la interesante intuición serleana acerca de buscar una nueva terminología para el sentido común, un juego de metáforas o formulaciones lingüísticas que nos permita un mejor acceso a la realidad y, por qué no, a su fundamento último, la verdad (como sea que la entendamos, si estática o eternamente mutable (provisoria)). Esta concepción más sofisticada de las cosas habla muy promisoriamente, por lo demás, con aquella vindicación que hace Habermas sobre el aprovechamiento práctico del vasto conocimiento tecnocientífico.

Es así que me permito concluir sobre la necesidad de soportar el proceso filosófico sobre una suerte de "conexionismo controlado", heurístico en todo caso, remitiendo el corpus filosófico a tantas fuentes o bases (académicas y no académicas) como sea posible para un desarrollo sistemático e integrado de todo su espectro de alternativas. (Entiendo por "heurística" un procedimiento para la resolución de un problema de alta complejidad con miras a la optimización, pero sin garantía de alcanzar el mejor resultado, mediante una aproximación intuitiva de la "bondad" del resultado que permita al menos observar las diferencias entre el camino solutivo propuesto y aquel que se intenta superar). En ningún caso propongo un conexionismo cuyas extensiones 
se diseminen estérilmente, como aquel de carácter divergente que critica Dennett, sino uno que opere en las antípodas, sintetizando ideas que permitan la forja de sistemas de envergadura y con ello el progreso concreto de la filosofía.

Un órganon como el que refiero tendría, en consecuencia, la propiedad de hacer intercambios informacionales ordenados en tiempo real entre sus depósitos teoréticos y de sintetizar, de acuerdo a los criterios de verdad que apliquen a cada rama, extensión o subsistema filosófico, las ideas que contribuyan a su desarrollo, e incluso sintetizar ideas que den origen a categorías enteramente nuevas que hagan posible la apertura de extensiones más sofisticadas del sistema filosófico civilizatorio. Claramente resultan insuficientes los intelectos interactuando en su estado natural y no está claro hasta qué punto los recursos aumentadores disponibles en la actualidad tales como el paper, los repositorios de investigación, los sistemas de indexación y las redes sociales, integrados según una configuración específica, sirvan al propósito descrito. Es probable que se requiera de una innovación tecnológica inaudita para "hacer conversar" las diferentes alternativas cognitivas y aún más, para crear otras nuevas y, si fuera el caso, determinar el primado entre ellas para alguna aplicación social concreta.

Como fuere, la complejidad del macrosistema no solo ha de venir de las fórmulas con las que pensamos en tanto que autores, sino también, como se ha dicho, de las fuentes de las que bebemos, lo que dice relación con el vínculo práctico-social de la filosofía histórica, según Habermas. El tipo de repertorios desde los que una filosofía renovada conformaría su acervo serían, entre otros:

- La tradición filosófica (hoy asimilada en la filosofía académica).

- La tecnociencia.

- El arte.

- Las formas no canónicas de hacer filosofía.

- La correlación artificial entre ideas, constructos o variables filosóficas.

Con formas no canónicas de filosofar abro la puerta a reflexiones filosóficas que no se llevaran a cabo por la vía de los métodos tradicionales, pero que serían tan intuitivas y enriquecedoras como las que resultan de estos. Un ejemplo de estas filosofías "díscolas" sería Psycho-Pass, si el objeto de esta serie fuera la reflexión filosófica, lo que no parece ser el caso (es más bien una producción artística con tintes filosóficos). $\mathrm{O}$ el mismo Nietzsche en Así habló Zaratustra, donde expresiones como "la vaca multicolor" o "el eterno retorno" disparan toda una serie de interpretaciones posibles, cada una de las cuales puede estudiarse bajo los procedimientos analíticos, por ejemplo. Y para que no quepan dudas del poder que pudiera implicar la atracción de estas formas de filosofía al gran sistema filosófico de la civilización, me permito citar la intuición que entraña una observación que se hace en el videojuego Mirror's Edge Catalyst (Jansson y Juhlén 2020) de la desarrolladora sueca EA Digital Illusions CE - otra distopía futurista- cuando, avanzada la trama, una hacker ayuda a colarse a la protagonista en el servidor de la compañía Kruger Security. Allí, frente a la sorpresa de esta última por lo intrincado y enorme del área, la programadora arguye que se trata de algo perfectamente inteligible 
y ordenado para los sistemas de IA que soporta. "Sí, bueno, no fue diseñado pensando en los humanos. Espacio para máquinas. Eficiencia pura. Seguro que es precioso", dice. Se trata en este caso de una reflexión sobre todo atinente a la filosofía de la técnica: un mundo material que sirve ya de manera palmaria antes a la tecnología que a los humanos. La técnica, en ese escenario, ha adquirido además un estatuto inteligente.

Finalmente la correlación artificial entre ideas bien puede tantearse bajo el amplio paraguas de la IA. Porque así como en la analítica de datos que llevan a cabo los departamentos de business intelligence (BI) de las empresas (forecasting, datamining, On-Line Analytical Processing, entre otras técnicas) o la que consuman las ciencias físico-naturales sobre inconmensurables bases de datos con procedimientos tanto o más enrevesados, y que a menudo se sintetizan en gráficos inteligibles como los que presentan los artículos de las revistas Forbes y Nature, respectivamente, así también la filosofía podría ya comenzar a pensar un modo de correlacionar sus conceptos, con un nivel de complejidad creciente de su capacidad ordinaria de análisis, de una manera que resulte a la vez insospechada y sugerente a la intuición, aconsejando vínculos y solapamientos imprevistos entre tesis y antítesis. Estas constataciones, sí, serían o no ratificadas por el intelecto en su estado natural (o por el intelecto aumentado según sus recursos presentes) y, de ser viables, refrendarían el rendimiento de una teórica tecnología de última generación a la misión filosófica. Se trata, si se quiere, de una inversión del giro que la técnica contemporánea ha adoptado, según Sadin (2018), inscribiéndola otra vez en la esfera de acción humana. A juicio del francés, la potencia computacional para desencriptar estas "afinidades secretas" existe:

Los procesadores [actuales] se presentan como sustratos externos destinados a ampliar o a profundizar nuestra intuición general de las cosas; se les concede no la capacidad de pensar según una dimensión reflexiva, sino la de develar la naturaleza compleja de algunas de nuestras acciones, y perciben con mayor precisión quizá, ciertas cuestiones decisivas e insospechadas de nuestras realidades (p. 65).

Por supuesto, el mismo Sadin advierte que este tipo de "intuición computacional" no puede equipararse en modo alguno a la "intuición humana", ya que se trata siempre de una mera reducción matemático-binaria de la inteligencia de la técnica, por muy sofisticado que sea el despliegue de sus funcionalidades. En sus palabras:

La delegación de poder otorgada a los procesadores enmascara en negativo una concesión operada sobre la calidad de las percepciones colectivas e individuales basadas sin cesar en procesos estimativos fácticos incapaces de aprehender plenamente la realidad multiestratificada de nuestras realidades (p. 119).

Conviene advertir que si bien Sadin nos habla de procesadores, no son estos en sí mismos entidades "inteligentes", sino que ellas resultan de una innatural federación de sistemas y procesos computacionales desperdigados que, vistos globalmente en sus efectos sobre la humanidad, ofrecen funcionalidades aparentemente propias de un sirviente "inteligente". Aisladamente, estos procesadores no son más que esclavos bien adiestrados en aspectos muy específicos de la inteligencia. Tal sería el caso de la 
inferencia en tiempo real de los estados emocionales de una multitud de personas que atraviesan el lente de una serie de dispositivos de control biométrico. Esta multiplicación de la capacidad inferencial de un individuo técnicamente reducida ("aumentación", la denomina Sadin) debe ponderarse con la posibilidad de los efectos benignos que podría producir, por otro lado, una interacción humano-computacional (HCI) sobre la base de una IA genuinamente antropomórfica que cooperara con la humanidad, como es la que propone el Dr. Mark Sagar, CEO de Soul Machines, a partir de sus avatares construidos sobre una simulación digital del sistema nervioso (Downey et al. 2020). Una IA de esta índole, "humanizada" más bien que "aumentada", podría, de cooperar efectivamente, darnos luces en lenguaje "humano" acerca de lo que es o no inherente a nuestra condición y cuándo la misma se ve sobrepasada y acaba por abdicar en el cyborg o lo técnicoinhumano (hablo derechamente aquí de la posibilidad de un filósofo "artificial"). No ocurre esto, en cambio, con la IA de Sadin que, aun cuando su potencia nos desborda, la misma pasa desapercibida por los mecanismos "soft", justamente devenidos de su naturaleza desestructurada, a través de los cuales echa raíces en nuestra civilización.

Con todo, la pura constatación del tipo de conocimiento teórico que se postula, es decir, de estos "saberes" que resultan de la optimización de los medios de producción filosófica, y del asombro que en los filósofos podría engendrar un hipotético aumento de su productividad así como las características privativas de los nuevos relacionamientos entre categorías y reflexiones que estarían a su alcance, servirían para entender mejor el tipo de relación que se da a su vez entre filosofía y técnica, lo que de suyo entraña al menos la posibilidad de una recapacitación de la disciplina con respecto a sus métodos, vehículos de producción y jerarquías y divisiones funcionales.

Para concluir, quisiera señalar que a una filosofía como la expuesta, si bien heurística, puede arrogársele el carácter de optimizadora cuando menos porque aúna todas las fuentes potenciales del filosofar, y contiene también el presupuesto de que aquellos que siendo parte de la forma canónica de filosofar decidieran migrar a la forma no canónica, lo harían teniendo un mejor desempeño en esta última al resultarles más favorable el formato de producción.

Pero lo anterior implica sobre todo la participación y adherencia de la sociedad civil con vistas a ensayar un alcance humanitario de la filosofía.

De esta forma -y si lo que se busca es conservar la gobernabilidad en el procesose requiere también la aquiescencia de los poderes de hecho y derecho que imperan sobre las instituciones de orden político e intelectual. De esta suerte, me permito resumir las condiciones que el Dr. Pablo Razeto del Instituto de Filosofía de Ciencias de la Complejidad (IFICC) defiende para los cambios estructurales de las sociedades, basadas en el análisis de estas transformaciones efectuado por Antonio Gramsci (Razeto 2020).

Gramsci, según Razeto, sostiene que los cambios estructurales tienen una triple vertiente que los hace posibles. Por un lado, los modelos de alta cultura, que son aquellos diseñados por la élite intelectual y que beben con mayor o menor inmediatez de las demandas ciudadanas. Por otro, los movimientos populares, que son la expresión política inmediata de las necesidades de la sociedad civil y que establecen igualmente una relación bilateral con los modelos de alta cultura. Estos dos polos, el político y el 
intelectual, están representados en una tercera fuente, que tiene un carácter híbrido, también indefectible, la de los “intelectuales orgánicos", que son a la vez eruditos y agentes de cambio.

La transformación tiene lugar en la correspondencia que se establece entre los propulsores del cambio y las instituciones que encarnan la configuración actual del orden sociopolítico. Dicho contacto puede adquirir la forma de opresión mutua (revolución, invasión, guerra civil, golpe militar, etc.), persuasión (a través de la resistencia civil ética, como la que ejemplaron Gandhi, Martin Luther King y Mandela, y más recientemente el colectivo feminista de Valparaíso, en Chile, denominado "Lastesis", con el objetivo de manifestarse contra las violaciones a los derechos de las mujeres en el contexto del denominado "Estallido social" de ese país (Rodríguez 2019)) y/o sufragio.

Finalmente, extrapolado al contexto intelectual que tratamos aquí, la instauración de una nueva filosofía, como la descrita, requiere al menos cumplir las siguientes seis condiciones:

1. El diseño del modelo base.

2. La difusión del modelo.

3. La persuasión de las sociedades filosófica y civil y de sus instituciones.

4. La voluntad de las instituciones para someter a crítica los argumentos que se les presentan y máxime sus posiciones políticas e intelectuales, así como para reconocer sus imposturas.

5. La confianza en la legitimidad de la producción sistémico-tecnológica de los contenidos filosóficos basada en IA.

6. La adopción del modelo por parte de las sociedades filosófica y civil.

Estos, aunque consabidos, serían los requerimientos mínimos de una filosofía para estatuirse racionalmente como un sistema civilizatorio sobre la base de una aceptación popular generalizada.

\section{Referencias bibliográficas}

Aranda, Alfredo (17 de agosto de 2019), “¿Dónde está mi ‘Chief Happiness Officer’?”, Forbes. Recuperado de $<$ https://forbes.es/ $>$

Carmona, Carla (2017), Wittgenstein: La consciencia del límite. Barcelona: Emse Edapp.

Dal Maschio, Eduardo (2019), Platón: La verdad está en otra parte. Barcelona: Emse Edapp.

Dennett, Daniel C. (1999), "Cuando los filósofos se encuentran con la inteligencia artificial”, en H. L. Dreyfus, D. C. Dennett, H. Putnam y otros, ed., El nuevo debate sobre la inteligencia artificial. Barcelona: Gedisa, pp. 320-335. 
Downey Jr., Robert, Downey, Susan, Gertz, Paul, Murray, Derik, Foley, Sean, Motskin, Yon, Ford, Emily, Lanier, Cory, y Lesinski, Tom [productores ejecutivos] (2020), The Age of AI: How Far is Too Far? [serie tv]. EE.UU.: Network Entertainment, Sonar Entertainment y Team Downey.

Eco, Umberto (1993), Lector in fabula. Barcelona: Lumen.

Fuentes, Juan (2013), "La ilustración en el pensamiento de John Stuart Mill”, Cuadernos Salmantinos de Filosofia 40: 307-321.

Habermas, Jürgen (1971), "Wozu noch Philosophie?”, Philosophischpolitische Profile. Frankfurt: Suhrkamp; pp. 11-36. (En español: (2000). Perfiles filosóficos politicos. Madrid: Taurus; pp. 21-40).

(1999), Problemas de legitimación en el capitalismo tardio. Madrid: Cátedra.

Jansson, Sara [productora] y Per Juhlén, dir. (2016), Mirror's Edge Catalyst [videojuego]. EE.UU.: Electronics Arts.

Laloux, Frederic (2017), Reinventar las organizaciones. Madrid: Arpa.

Razeto, Pablo (Enero de 2020), “Gobernabilidad y política de la persuasión”, en A. Squella (Presidencia), IX Congreso Futuro (Panel 10: Gobernar). Santiago, Chile.

Reguero, Patricia (17 de noviembre de 2017), "Recogen 370.000 firmas contra Butler y queman una imagen de la filósofa en Brasil”, El Salto. Recuperado de $<$ https://www.elsaltodiario.com/>

Robbins, Stephen, y Timothy Judge (2009), Comportamiento Organizacional. Ciudad de México: Pearson Educación.

Rodríguez, Darinka (28 de noviembre de 2019), "Ellas son las chilenas que crearon 'Un violador en tu camino"”, El País. Recuperado de <https://verne.elpais. $\mathrm{com} />$

Rubio, Gabriel (2018), Fobias: Nuestros miedos irracionales vistos desde una perspectiva neurocientifica. Barcelona: Emse Edapp.

Sadin, Eric (2018), La humanidad aumentada: La administración digital del mundo. Buenos Aires: Caja Negra.

Sánchez, Cristina (2019), Simone de Beauvoir: Del sexo al género. Barcelona: Emse Edapp.

Searle, John (1999), “The future of philosophy", Philosophical Transactions: Biological Sciences, Vol. 354, No 1392: 2069-2080.

Segovia, Fausto (11 de marzo de 2016), "La semiótica o el eco de Umberto Eco", El Comercio. Recuperado de <http://www.elcomercio.com/>

Shiotani, Naoyoshi, Kiyotaka Suzuki, dirs., y Koji Yamamoto, productor (2014), Psycho-Pass [serie de tv]. Japón: Fuji TV (NoitaminA).

Solé, Joan (2019), Kant: El giro copernicano en la filosofía. Barcelona: Emse Edapp. 